Minami et al., Afr J Tradit Complement Altern Med. (2015) 12(6):131-139

http://dx.doi.org/10.4314/ajtcam.v12i6.13

\title{
EFFECT OF SHIN'ISEIHAITO ON LUNG COLONIZATION OF PNEUMOCOCCUS IN MURINE MODEL
}

\author{
Masaaki Minami ${ }^{{ }^{*}}$, Toru Konishi ${ }^{2}$, Zhixia Jiang ${ }^{3}$, Tetsuya Arai $^{3}$, Toshiaki Makino ${ }^{2}$. \\ ${ }^{1}$ Department of Bacteriology, Graduate School of Medical Sciences, Nagoya City University, 1 Kawasumi, Mizuho-ku, \\ Nagoya, Japan. \\ ${ }^{2}$ Department of Pharmacognosy, Graduate School of Pharmaceutical Sciences, Nagoya City University, 3-1 Tanabe-Dori, \\ Mizuho-ku, Nagoya, Japan \\ ${ }^{3}$ R\&D Center, Kobayashi Pharmaceutical Co., Ltd, 4-10 Doshomachi 4-chome, Chuo-ku, Osaka, Japan \\ Corresponding*E-mail: minami@med.nagoya-cu.ac.jp
}

\begin{abstract}
Background: Streptococcus pneumoniae (pneumococcus) causes various serious diseases including sinusitis, pneumonia, and meningitis. One serious problem observed recently with pneumococcal therapy is attenuation of the antibiotic effect because of the emergence of antibiotic-resistant pneumococcus. Shin'iseihaito, a traditional Japanese medicine based on ancient Chinese medicine, has been used for treatment of otolaryngeal diseases in Japan. The objective of this study was to examine the anti-infectious effects of shin'iseihaito and its related mechanism.

Materials and Methods: We evaluated the beneficial effect of shin'iseihaito extract (SSHT) against pneumococcus-infected murine model. The colonization of bacteria, blood and bronchoalveolar lavage (BAL) killing activity, the levels of inflammatory cytokine and IgA were investigated.

Results: The pneumococcus from blood was not found in both SSHT-treated mice and untreated mice. However, the pneumococcal colonization of lung was significantly $(p<0.05)$ lower after SSHT administration compared with untreated mice. Blood bactericidal assay showed that no significant difference $(p=0.07)$ was observed in the anti-bacterial effect between SSHT-treated mice and untreated mice. However, BAL bactericidal assay showed that the survival rate of pneumococcus using the BAL from SSHT-treated mice was significantly $(p<0.05)$ lower than that using the BAL from untreated mice. We also found increased levels of tumor necrosis factor (TNF)- $\alpha$, interleukin (IL)-1 $\beta$, and IgA in pneumococcus-infected mice treated with SSHT.

Conclusions: SSHT decreased the colonization rate after pneumococcal infection and up-regulated BAL bactericidal activity through modulation of inflammatory cytokines and IgA. Our data also suggest SSHT may be useful for the treatment of pneumococcal infection.
\end{abstract}

Key words: shin'iseihito, Streptococcus pneumoniae, murine model, inflammatory cytokine, IgA

\section{Introduction}

Streptococcus pneumoniae (pneumococcus) caused several infectious diseases such as pneumonia, septicemia, and meningitis (Kadioglu et al., 2008). The emergence of antibiotic resistance among pneumococcal isolates has been of great concern (Minami et al., 2014). This is further shown by the increasing incidence of penicillin-resistant, macrolide- resistant, and multidrug-resistant pneumococcus (Cottagnoud et al., 2003; Yasuda et al., 2007; Minami et al. 2015). Inadequate conventional antibiotic therapy is likely involved in the risk of exacerbating the disease in cases of infection with antibiotic-resistant pneumococcus.

Shin'iseihaito (xinyiqingfeitang in Chinese), a formula consisting of nine crude drugs, has been used for the treatment of nasal diseases such as chronic sinusitis in traditional Japanese kampo medicine and traditional Chinese medicine (Majima et al., 1992; Kato et al., 1994). The part of formula name (seihai) expressed the clearing of lung. Thus this formula may potentially possess the effect of pneumonia treatment. However, shin'iseihaito has not been investigated for its role in anti-pneumococcal therapy.

Murine model has been used to assess the therapeutic efficacy of traditional Kampo medicine including immunological mechanism of action (Makino et al., 2005; Makino et al. 2014; Tsukamoto et al., 2014). In such studies, several infectious murine experiments revealed the mechanism of traditional Kampo medicine (Minami et al., 2011; Dan et al., 2013). However, the effects of shin'iseihaito on ameliorating the pneumococcus-infected model have not been previously reported. In this study, we investigated the beneficial effects of shin'iseihaito on pneumococcal murine model.

\section{Materials and Methods Bacterial}

Streptococcus pneumoniae ATCC49619 was type 19A cps isolates from sputum. A fresh colony was inoculated overnight on trypticase soy agar with 5\% sheep blood (Nihon Becton Dickinson, Tokyo, Japan) and cultured for 16 hour at $37^{\circ} \mathrm{C}$. The bacteria were harvested by centrifugation and re-suspension in sterile saline. The bacterial suspension was then diluted with saline to $10^{9} \mathrm{CFU}$ (colony forming unit)/mL using a standard growth curve to relate measured A600 to bacterial concentration. 
Minami et al., Afr J Tradit Complement Altern Med. (2015) 12(6):131-139

\section{http://dx.doi.org/10.4314/ajtcam.v12i6.13}

\section{Animals}

Three to four - week old female ICR mice (Japan SLC Inc., Shizuoka, Japan) were used. All experimental procedures were conducted according to Nagoya City University Guidelines for the Care and Use of Laboratory Animals, and the study protocol was approved by the local Animal Ethics Committee in Nagoya City University.

\section{Drugs}

Shin'iseihaito consists of $3.0 \mathrm{~g}$ (daily dose for human) of Gypsum fibrosum (sekko in Japanese, shigao in Chinese, respectively), $3.0 \mathrm{~g}$ of tuber of Ophiopogon japonicus (bakumondo, maimendong), $1.5 \mathrm{~g}$ of root of Scutellaria baicalensis (ogon, huangqin), $1.5 \mathrm{~g}$ of rhizome of Anemarrhena asphodeloides (chimo, zhimu), $0.75 \mathrm{~g}$ of fruit of Gardenia jasminoides (sanshishi, zhizi), $1.5 \mathrm{~g}$ of bulb of Lilium lancifolium (baimo, baihe), $1.5 \mathrm{~g}$ of flower of Magnolia salicifolia (shin'i, xinyi), $0.5 \mathrm{~g}$ of leaf of Eriobotrya japonica (biwayo, pipaye), $0.75 \mathrm{~g}$ of rhizome of Cimicifuga heracleifolia (shoma, shengma). These crude drugs were mixed, boiled, filtered, and the decoction was dried to yield powdered extract (SSHT, $2.5 \mathrm{~g}$ for daily human dose). SSHT (Lot: 14B019) was provided as a generous gift from the Kobayashi Pharmaceutical Co., LTD (Osaka, Japan). SSHT was suspended in distilled water to prepare the stock solution at a concentration of $0.1 \mathrm{~g} / \mathrm{mL}$ and kept in $-20^{\circ} \mathrm{C}$ until use.

\section{Animal Treatments Protocol}

The experimental timetable is provided in Figure 1. Pneumococcus-infected murine model was established based on the previously described methods with minor modifications (Cottagnoud et al., 2003; Yasuda et al., 2007). The mice were randomly divided into three groups (control group, pneumococcus-infected group, and SSHT-treated pneumococcus-infected group). In brief, pneumococcus was harvested after 16-hour growth on trypticase soy agar with $5 \%$ sheep blood and then collected and centrifuged at 2,000 x $g$ for 2 min. The pellets were diluted in $1.0 \mathrm{~mL}$ saline to $1 \times 10^{9} \mathrm{CFU}$ and then followed by injections of bacteria $(10 \mu \mathrm{L} /$ each nostril) into nostrils of mice using a 29 -gauge needle at day 0 . The number of CFU injected was verified for each experiment by plating the bacteria on trypticase soy agar with 5\% sheep blood and counting CFU. Mice were observed daily for general conditions such as body weight. In the SSHT-treated group, mice were force-fed SSHT $(10 \mathrm{mg} / 0.1 \mathrm{~mL} / 10 \mathrm{~g}$ body weight (bw)/day, 20-fold of human dosage) on days $-1,0,1,2$, and 3 after pneumococcus inoculation. Mice in the control group were given an equal volume of saline and were infected using the same method.

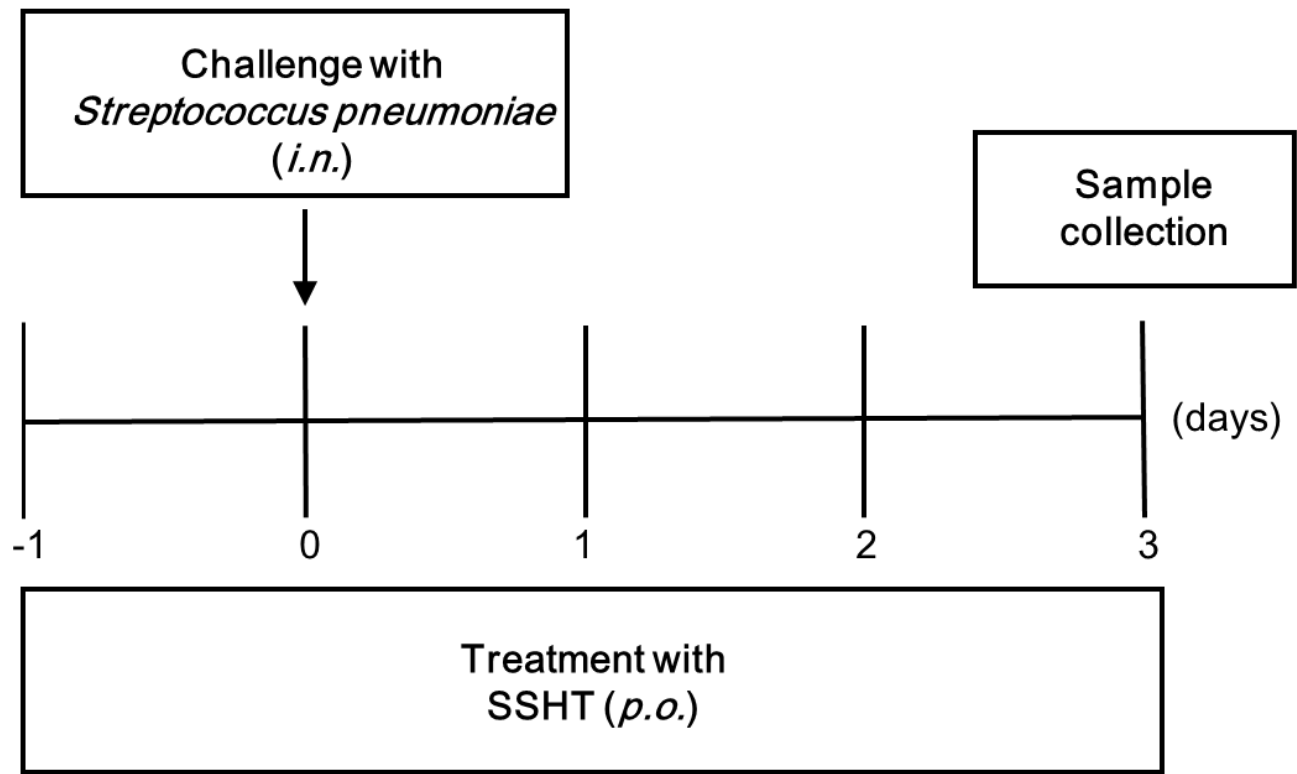

Figure 1: Challenge protocols for the experimental pneumococcal murine model.

In infected group, bacteria were injected into nostrils of mice using a 29 -gauge needle at day 0.

In the SSHT-treated group, mice were force-fed SSHT on days -1, 0, 1, 2, and 3 after pneumococcus inoculation. Mice in the control group were given an equal volume of saline and were infected using the same method 


\section{Minami et al., Afr J Tradit Complement Altern Med. (2015) 12(6):131-139 \\ http://dx.doi.org/10.4314/ajtcam.v12i6.13 \\ Preparation of Blood and BAL Samples}

Blood from both infected and treated/infected groups was collected under anesthesia at 3 days after infection. Each blood sample was centrifuged, and the resultant serum was stored at $-80^{\circ} \mathrm{C}$ until the day of assay (Minami et al., 2011).

The preparation of bronchoalveolar lavage (BAL) was performed as follows (Asanuma et al., 2001): A midline incision made over the ventral aspect of the trachea slightly anterior to the thoracic inlet allowed access to the trachea. A tracheotomy was made and $1 \mathrm{~mL}$ of saline was slowly injected cephalic through the upper respiratory tract via a 23 gauge indwelling needle (Terumo Co. Tokyo, Japan) attached to a tuberculin syringe (Terumo). The indwelling needle was then redirected distally and a BAL performed with $1 \mathrm{~mL}$ saline. This procedure was performed twice. Sera and BAL were stored at $-80^{\circ} \mathrm{C}$ until assayed.

\section{Assays to Determine Serum and BAL Cytokine}

We determined the levels of serum and BAL cytokines, such as tumor necrosis factor (TNF)- $\alpha$, interleukin (IL)- $1 \beta$, IL-6, and IgA during the course of infection in pneumococcus-infected mice treated with SSHT as described earlier (Minami et al., 2011). TNF- $\alpha$, IL-1 $\beta$, IL-6 (Biolengend Inc. CA. USA), and IgA (CUSABIO Biotech Co., Ltd., Wuhan, P. R. China) levels were determined by sandwich ELISA. For the assay, combinations of capture and biotinylated $\mathrm{mAb}$ were used as recommended by the manufacturer. Cytokine levels were calculated using standard murine recombinant cytokine curves run on the same immunoplate.

\section{Blood and BAL Bactericidal Assay}

Blood bactericidal assays were performed as an evaluation of whole blood bactericidal effect with some modification (Minami et al., 2011). In the SSHT-treated group, mice were force-fed SSHT $(0.1 \mathrm{~mL} / 10 \mathrm{~g}$ body weight (bw)) on 4 days before collection. Mice in the control group were given an equal volume of saline. Heparinized blood was collected from SSHT-treated and untreated mice not infected with pneumococcus. BAL was also collected from SSHT-treated and untreated mice not infected with pneumococcus as described above. Blood bactericidal assays were performed as follows; approximately $1000 \mathrm{CFU}$ of bacteria was added to $1 \mathrm{~mL}$ of heparinized mice whole blood. The samples were incubated at $37^{\circ} \mathrm{C}$ on a rotator. Aliquots were removed and plated on trypticase soy agar with 5\% sheep blood to determine the number of CFU after 0,30 and 60 min. Data were expressed as bacterial CFU counts at each times. BAL bacterial assay was performed by using BAL samples instead of blood. Other experimental condition in BAL bactericidal assay was same as that in blood killing assay.

\section{Data Analysis}

Experimental data were expressed as mean values with standard deviation (S.D.). Statistical analysis of the differences between the mean values obtained was performed using Turkey's multiple comparison tests and an unpaired Student's $t$-test with a significance level of $p<0.05$.

\section{Results \\ SSHT Inhibited the Colonization of Pneumococcus in Lung}

First of all, we investigated the change of survival rate and body weight in pneumococcal murine model. We did not find any death mice in this study. However, we found the significant decline of body weight after pneumococcus-infected mice compared to control mice $(p<0.05)$ [Figure 2]. But, there was no significant difference of murine body weight between pneumococcal infection and pneumococcal infection treated by SSHT ( $p$ $=0.78$ ). Thus we focused on the effect of SSHT on three days after pneumococcal infection. Next we investigated the CFU of blood and BAL 3 days after the pneumococcal infection [Figure 3A, 3B]. The pneumococcal CFU counts of blood were not detected in both infectious mice and infectious mice treated with SSHT. The pneumococcal CFU counts of BAL were significantly lower in infectious mice treated with SSHT than those in infectious mice $(p<0.05)$.

\section{SSHT Activated the BAL Killing}

To determine whether leukocytes in SSHT-treated mice show elevated bactericidal activity, we performed pneumococcus killing assays using mouse blood and BAL. As shown in Figure 4A, blood from untreated mice killed approximately $90 \%$ of the bacterial inoculum after 60 min incubation at $37^{\circ} \mathrm{C}$. Similar levels of pneumococcus killing were observed in the blood from mice treated with SSHT. Significant differences were not observed in the CFU reduction of pneumococcus between SSHT-treated and untreated mice [Figure 4A]. As shown in Figure 4B, BAL from untreated mice killed approximately $90 \%$ of the bacterial inoculum after 60 min incubation at $37^{\circ} \mathrm{C}$. However, the BAL from SSHT-treated mice killed approximately $99 \%$ of pneumococcus inoculum after $60 \mathrm{~min}$ incubation at $37^{\circ} \mathrm{C}$. Significant differences were observed in the CFU reduction of pneumococcus between SSHT-treated and untreated mice $(p<0.05)$ [Figure 4B]. 
Minami et al., Afr J Tradit Complement Altern Med. (2015) 12(6):131-139

http://dx.doi.org/10.4314/ajtcam.v12i6.13

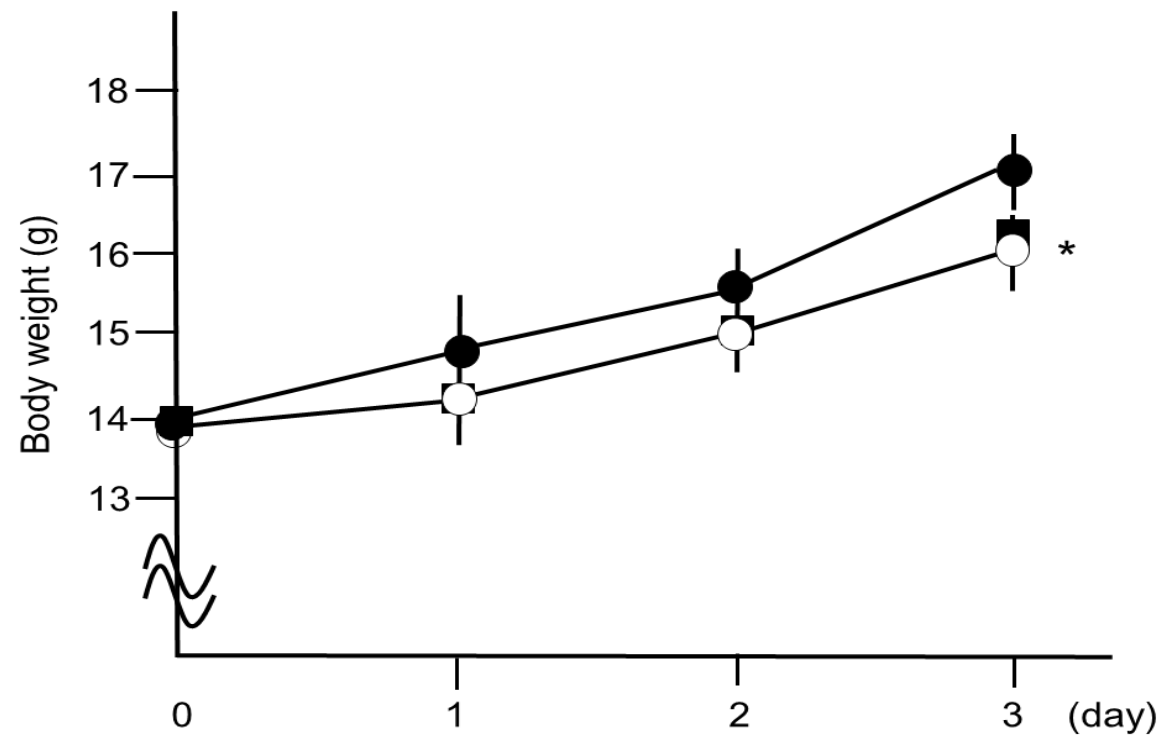

Figure 2: Effects of SSHT on body weight in pneumococcal murine model.

The mean values of pneumococcus infected group mice significantly decreased compared with that control group mice at day $3(* p<0.05)$. Closed circle; control mice, open circle; pneumococcus-infected mice, closed box; pneumococcus-infected mice treated with SSHT. Data represents the mean \pm S.D. of values in each group $(n=6)$.

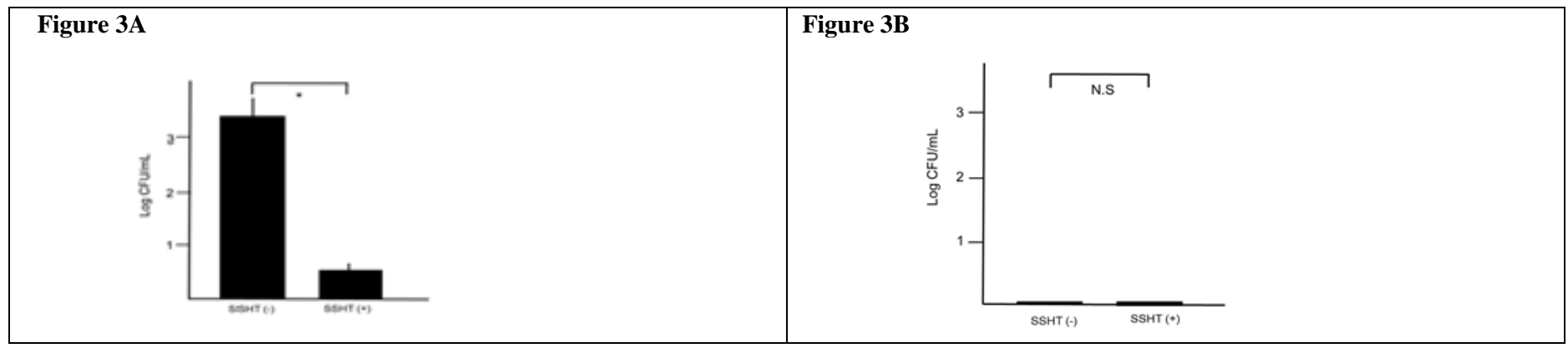

Figure 3: Effects of SSHT on bacteria CFU in pneumococcal murine model.

The mean values of bacteria CFU in SSHT treated pneumococcus-infected mouse significantly decreased compared with that in pneumococcusinfected mice. A: blood, B: BAL. Data represents the mean \pm S.D. of values in each group $(n=6) . *: p<0.05$, N.S., not significant. 
Minami et al., Afr J Tradit Complement Altern Med. (2015) 12(6):131-139

http://dx.doi.org/10.4314/ajtcam.v12i6.13

Figure 4A

Figure 4: Effects of SSHT on bacteria CFU by blood killing (A) and BAL killing (B) assay.

The mean values of bacterial CFU in SSHT treated mice significantly decreased compared with that control group mice in BAL. Closed circle; control mice, open circle; pneumococcus infected mice, closed box; pneumococcus infected mice treated with SSHT. Data represents the mean \pm S.D. of values in each group $(n=6) .\left({ }^{*} p<0.05 v s\right.$ untreated group)

\section{SSHT Up-Regulated the TNF- $\alpha$, and IL-1ß Productions and Down Regulated the IL-6 Levels of Infectious Mouse}

The TNF- $\alpha$ levels in sera were significantly higher in SSHT-treated uninfected mice than those in control mice $(p<0.05)$. Compared to infected mice, the infected mice treated with SSHT had also significantly increased TNF- $\alpha$ level in sera $(p<0.05)$ [Figure 5A, 5B]. The TNF- $\alpha$ levels in BAL were significantly higher in SSHT-treated mice than those in control mice $(p<0.05)$. Compared to infected mice, the infected mice treated with SSHT had also significantly increased TNF- $\alpha$ level in BAL $(p<0.05)$ [Figure 5C, 5D]. The IL-1 $\beta$ levels in sera were significantly higher in SSHT-treated uninfected mice than those in control mice $(p<0.05)$. Compared to infected mice, the infected mice treated with SSHT had also significantly increased IL- $1 \beta$ levels in sera $(p<0.05)$ [Figure 5E, 5F]. The IL-1 $\beta$ levels in BAL were not significantly higher in SSHT-treated uninfected mice than those in control mice $(p=0.37)$. However, compared to infected mice, the infected mice treated with SSHT had significantly increased IL-1 $\beta$ levels in BAL $(p<0.05)$ [Figure 5G, 5H]. The IL-6 levels in sera were significantly lower in SSHT-treated uninfected mice than those in control mice $(p<0.05)$. Compared to infected mice, the infected mice treated with SSHT had also significantly decreased IL-6 levels in sera $(p<0.05)$ [Figure 5I, 5J]. However, the IL-6 levels in BAL were not significantly lower in SSHT-treated uninfected mice than those in control mice $(p=0.15)$. Compared to infected mice, the infected mice treated with SSHT did not have also significantly decreased IL-6 levels in BAL $(p=0.25)$ [Figure 5K, 5L].

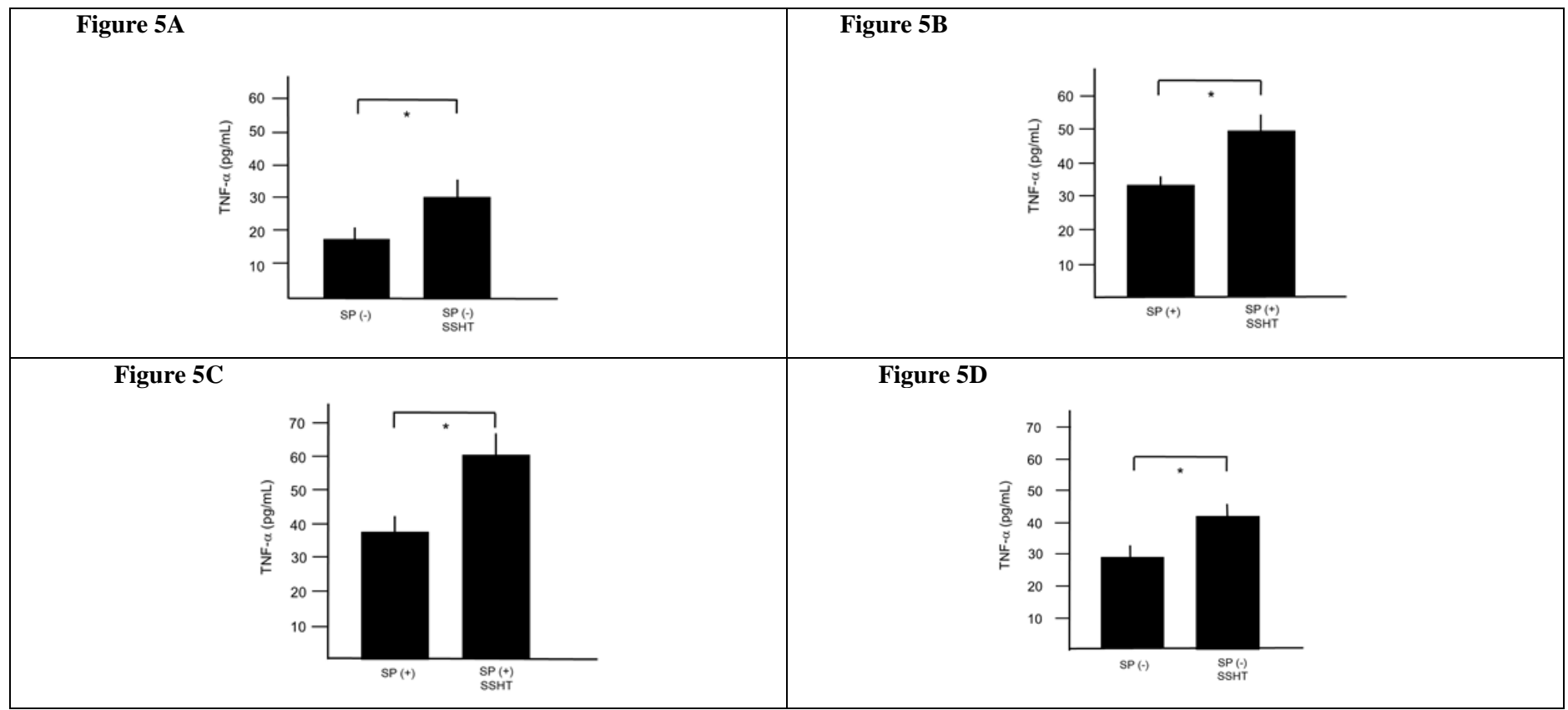


Minami et al., Afr J Tradit Complement Altern Med. (2015) 12(6):131-139

http://dx.doi.org/10.4314/ajtcam.v12i6.13

\begin{tabular}{|c|c|}
\hline 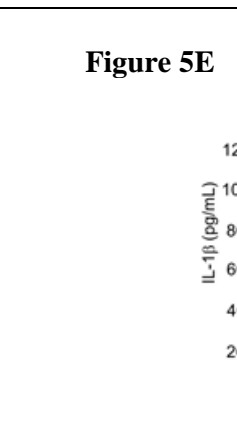 & 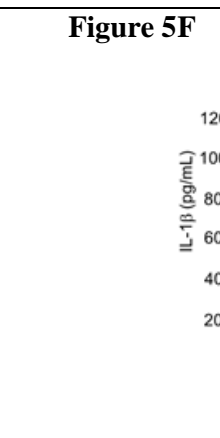 \\
\hline 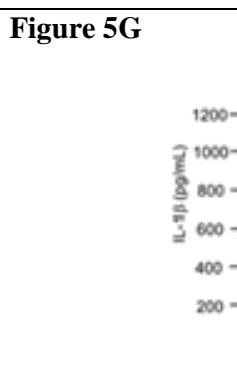 & Figure 5H \\
\hline Figure 5I & Figure 5J \\
\hline 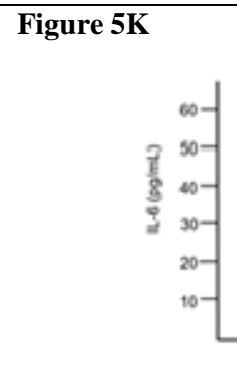 & 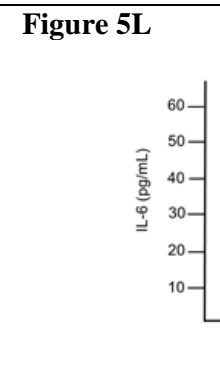 \\
\hline
\end{tabular}

Figure 5: Effects of SSHT on serum and BAL cytokine in pneumococcal murine model.

The mean values of TNF- $\alpha$ and IL-1 $\beta$ in SSHT-treated mice significantly increased compared with that control group mice in BAL. SP(-), uninfected mice; SP(+), infected mice. A, B; TNF- $\alpha$ in sera, C, D; TNF- $\alpha$ in BAL, E, F; IL-1 $\beta$ in sera, G, H; IL-1 $\beta$ in BAL, I, J; IL-6 in sera, K, L; IL-6 in BAL. Data represents the mean \pm S.D. of values in each group $(n=6) . * p<0.05$, N.S (not significant).

\section{SSHT Activated the IgA Levels of Infectious Mouse}

The IgA levels in sera were not significant higher in SSHT-treated uninfected mice than those in control mice $(p=0.27)$. However, compared to infected mice, the infected mice treated with SSHT had significantly increased IgA levels in sera $(p<0.05)$ [Figure 6A, 6B]. The IgA levels in BAL were not significant higher in SSHT-treated uninfected mice than those in control mice $(p=0.07)$. However, compared to infected mice, the infected mice treated with SSHT had significantly increased IgA levels in BAL $(p<0.05)$ [Figure 6C, 6D]. 
Minami et al., Afr J Tradit Complement Altern Med. (2015) 12(6):131-139

http://dx.doi.org/10.4314/ajtcam.v12i6.13

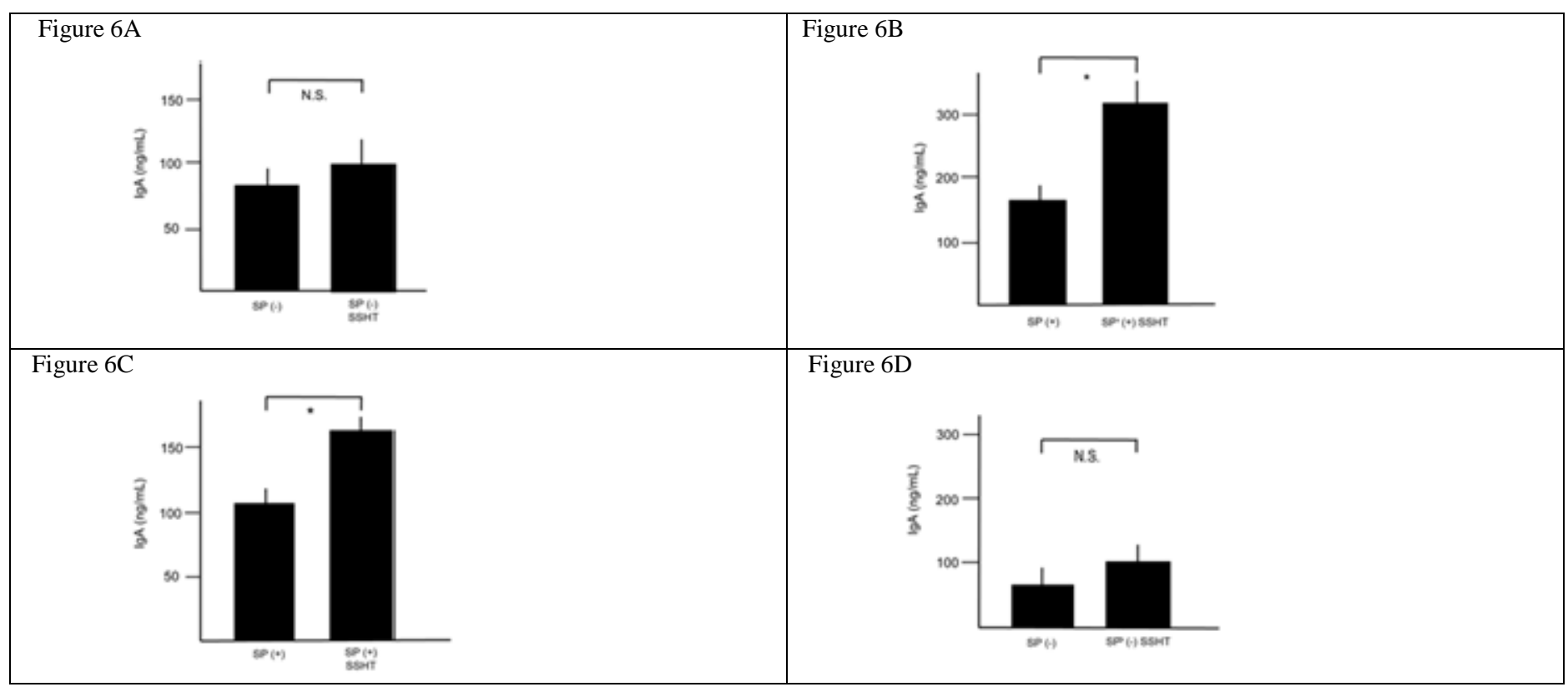

Figure 6: Effects of SSHT on serum and BAL IgA in pneumococcal murine model

The mean values of IgA in SSHT-treated mice significantly increased compared with that control group mice in BAL. SP(-), uninfected mice; SP(+), infected mice. A, B; IgA in sera, C. D; IgA in BAL. Data represents the mean \pm S.D. of values in each group $(n=6)$. ${ }^{*} p<0.05$, N.S., not significant.

\section{Discussion}

To our knowledge, this is the first study on anti-pneumococcus therapy with SSHT in murine model. After pneumococcal infection, SSHTtreated mice showed increased pneumococcal-clearing rate in lung, BAL bactericidal activity, levels of TNF- $\alpha$, IL-1 $1 \beta$, and IgA in serum. These results suggest that SSHT may play an important role in protection against pneumococcal infection.

Although there is a difference in degree, bacterial infection causes the tissue injury. Stress such as infection and injury induce an innate airway IgA response in severely human and mice. Secretory immunoglobulin A (sIgA) increases in the airways of humans and mice to protect against infection by blocking pathogen attachment to mucosal surfaces. The lymphocytes migrate through mesenteric lymph nodes, the thoracic duct and back into the blood stream and home to the lamina propria in the respiratory tract and intestine where the mature lymphocytes produce dimeric IgA. The pro-inflammatory cytokines TNF- $\alpha$, IL-1 $\beta$, and IL-6 affect both the production and the transport of IgA across the epithelial border (Jonker et al., 2011).

TNF- $\alpha$ and IL- $1 \beta$ blockade would blunt the airway IgA response in murine model. Stress significantly increased BAL IgA compared with baseline. Blockade of TNF- $\alpha$ eliminated the innate airway IgA response to injury, whereas IL- $1 \beta$ blockade blunted. TNF- $\alpha$ is involved in the respiratory IgA immune response to injury. TNF- $\alpha$ blockade impair this innate response, and blockade of IL-1 $\beta$ impairs it to a degree. These cytokines blunt this response via their known effects on the pIgR (Hermesen JL., 2008).

Other study showed that injured mice had significantly increased BAL fluid concentrations of TNF- $\alpha$, IL-1 $\beta$, and IL- 6 without significant changes in serum TNF- $\alpha$ or IL-1 $\beta$. But serum IL-6 increased significantly (Jonker et al., 2011). Although injury significantly increases human and mouse airway TNF- $\alpha$, IL-1 $\beta$, and IL-6, increases are greater in the airway than in serum, implying a local rather than a systemic stress response to injury (Jonker MA, 2011). Our results showed that the levels of TNF- $\alpha$, IL-1 $\beta$, and IL-6 in lung colonization are higher than those in control in BAL. But, in sera, the levels of IL-6 in lung injury are only higher than that in control. Our results are coincided with previous results.

In IgA-secretory pass way, TNF- $\alpha$ and IL-1 $\beta$ stimulates the production of polymeric immunoglobulin receptor (pIgR) via the nuclear factor-kappa B (NF-KB) passway (Schjervenet al., 2001). The IgA binds to pIgR located on the basolateral surface of epithelial cells. The pIgR has 7 domains: 5 extracellular, 1 transmembrane and 1 cytoplasmic. This pIgR-IgA complex is endocytosed by epithelial cells, and transported to the apical cell surface. The complex is released into the lumen as secretory IgA by cleavage of the extracellular part of pIgR (Norderhaug et al., 1999). Although we have not concerned the relationship between SSHT and pIgR yet, the further investigation of the relationship between SSHT and pIgR is desired. 


\section{Minami et al., Afr J Tradit Complement Altern Med. (2015) 12(6):131-139}

\section{http://dx.doi.org/10.4314/ajtcam.v12i6.13}

Previous reports showed the role of lung lymphocytes in the local defense mechanisms by the natural antibacterial activity of mouse lung lymphocytes with an in vitro assay using pneumococcus (Sestina et al., 1987; Sestina et al., 1988). Preincubation of lung lymphocytes with anti-IgA antibodies completely inhibited natural antibacterial activity. Furthermore, purified IgA from plasmacytoma with specificity for phosphorylcholine, a component of the outer wall of pneumococcus, was able to enhance the antibacterial activity of lung lymphocytes and to restore their activity after treatment with anti-IgA (Sestina et al., 1987; Sestina et al., 1988). In our study, the colonization of pneumococcus in lung was significant inhibited in SSHT extract-treated mice and the IgA level of BAL was upregulated in SSHT-treated mice. Those results may explain that SSHT affects the role of lung lymphocytes in the local defense mechanism.

Our results revealed that SSHT enhances the mucosal IgA immune response. SSHT consists of nine-component crude drugs, and is known to contain various compounds, which may possess immunomodulatory effects. Therefore, these may complicate the interpretation of results. At this point, several possibilities can be considered. One of them is that SSHT extract acts as a polyclonal B cell stimulator. Previous report showed that wogonin isolated from root of Scutellaria baicalensis, which is one of componential crude drugs of SSHT, may play a role in the enhancement of IgA response via a polyclonal B cell activation as active constituents in SSHT (Lim., 2004). The precise mechanism of enhancement of IgA response by SSHT still remains obscure. To elucidate the action mechanisms of SSHT and active constituents in SSHT, further investigations are necessary.

In conclusion, the data in the present study suggest that SSHT may prove useful in the amelioration and/or prevention of pneumococcus. However, further investigation will be necessary to elucidate the molecular mechanisms of SSHT against pneumococcal infection.

\section{Acknowledgements}

We thank Mr. Masashi Ishihara and Ms. Miwako Fujimura for excellent support through this investigation. This study was supported by the Foundation of Oriental Medicine Study.

\section{References}

1. Asanuma, F., Kuwabara, K., Arimura, A., Furue, Y., Fleisch, J.H., and Hori, Y. (2001). Effects of leukotriene B4 receptor antagonist, LY293111 Na, on antigen-induced bronchial hyper responsiveness and leukocyte infiltration in sensitized guinea pigs. Inflamm. Res., 50(3):136-141.

2. Cottagnoud, P., Cottagnoud, M., Acosta, F., Flatz, L., Kühn, F., Stucki, A and Entenza, J. (2003). Meropenem prevents levofloxacin-induced resistance in penicillin-resistant pneumococci and acts synergistically with levofloxacin in experimental meningitis. Eur. J. Clin. Microbiol. Infect. Dis., 22(11):656-662.

3. Dan, K., Akiyoshi, H., Munakata, K., Hasegawa, H., and Watanabe, K. (2013). A Kampo (traditional Japanese herbal) medicine, Hochuekkito, pretreatment in mice prevented influenza virus replication accompanied with GM-CSF expression and increase in several defensing mRNA levels. Pharmacology, 91(5-6):314-321.

4. Hermsen J.L., Sano Y., Gomez F.E., Maeshima Y., Kang W., and Kudsk K.A. (2008). Parenteral nutrition inhibits tumor necrosis factor-alphamediated IgA response to injury. Surg. Infect. (Larchmt), 9(1):33-40.

5. Jonker M.A., Hermsen J.L., Gomez F.E., Sano Y., and Kudsk K.A. (2011). Injury induces localized airway increases in pro-inflammatory cytokines in humans and mice. Surg. Infect. (Larchmt), 12(1):49-56.

6. Kato, M., Hattori, T., Kitamura, K., Beppu, R., and Yanagita, N. (1994). Effectiveness of Shin'i-Seihai-To for sinusitis with polyp. Jibirinsyo, 87(4):561-658.

7. Kadioglu, A., Weiser, J.N., Paton, J.C., and Andrew, P.W. (2008). The role of Streptococcus pneumoniae virulence factors in host respiratory colonization and disease. Nat Rev Microbiol, 6(4):288-301.

8. Lim B.O. (2004). Efficacy of wogonin in the production of immunoglobulins and cytokines by mesenteric lymph node lymphocytes in mouse colitis induced with dextran sulfate sodium. Biosci. Biotechnol. Biochem., 68(12):2505-2511.

9. Majima, Y., Sakakura, Y., Hamaguchi, F., and Murai, S. (1992). Shin'i-Seihai-To (TJ-104) treatment of chronic sinusitis. Jibirinsyo, 85(8):1333-1340.

10. Makino, T., Sasaki, S., Ito, Y., and Kano, Y. (2005). Pharmacological properties of traditional medicine (XXX): effects of Gyokuheifusan on murine antigen-specific antibody production. Biol. Pharm. Bull., 28(1):110-113.

11. Makino, T., Shiraki, Y., Mizukami, H. (2014). Interaction of gypsum and the rhizome of Anemarrhena asphodeloides plays an important role in anti-allergic effects of byakkokakeishito in mice. J. Nat. Med., 68(3):505-512.

12. Minami M., Ichikawa M., Hata N., and Hasegawa T. (2011). Protective effect of hainosankyuto, a traditional Japanese medicine, on Streptococcus pyogenes infection in murine model. PLoS One, 6(7):e22188.

13. Minami, M., Sakakibara, R., Imura, T., Morita, H., Kanemaki, N. and Ohta, M. (2014). Prevalence and Antimicrobial Susceptibility Pattern of Streptococcus pneumoniae at General Hospital in the Central Region of Japan from December 2013 to February 2014. J. Biosci. Med., 2:12-17.

14. Minami, M., Sakakibara, R., Imura, T., Morita, H., Kanemaki, N. and Ohta, M. (2015). Relationship between clinical characteristics and multidrug-resistant patterns of Streptococcus pneumoniae in Japan. Int. J. Curr. Res. Biosci. Plantbiol., 2(4): 92-98.

15. Norderhaug, I.N., Johansen, F.E., Schjerven, H., and Brandtzaeg, P. (1999). Regulation of the formation and external transport of secretory immunoglobulins. Crit. Rev. Immunol., 19(5-6):481-508.

16. Schjerven, H., Brandtzaeg, P., and Johansen, F.E. (2001). A novel NF- $\kappa B /$ Rel site in intron 1 cooperates with proximal promoter elements to mediate TNF- $\alpha$-induced transcriptionof the human polymeric Ig receptor. J. Immunol., 167(11):6412-6420. 
Minami et al., Afr J Tradit Complement Altern Med. (2015) 12(6):131-139

http://dx.doi.org/10.4314/ajtcam.v12i6.13

17. Sestini P., Nencioni L., Villa L., Boraschi D., and Tagliabue A. (1987). Antibacterial activity against Streptococcus pneumoniae by mouse lung lymphocytes. Adv. Exp. Med. Biol., 216A:517-525.

18. Sestini P., Nencioni L., Villa L., Boraschi D., and Tagliabue A. (1988). IgA-driven antibacterial activity against Streptococcus pneumoniae by mouse lung lymphocytes. Am. Rev. Respir. Dis., 137(1):138-143.

19. Tsukamoto, K., Yamamoto, K., and Makino, T. (2014). Counteractive effect of Paeonia lactiflora root constituent mudanpioside E against suppressive effect of shoseiryuto-extract on passive cutaneous anaphylaxis reaction in mice. J. Ethnopharmacol, 153(3):884-889.

20. Yasuda, Y., Kasahara, K., Mizuno, F., Nishi, K., Mikasa, K., and Kita, E. (2007). Roxithromycin favorably modifies the initial phase of resistance against infection with macrolide-resistant Streptococcus pneumoniae in a murine pneumoniae model. Antimocrob. Agents Chemother., 51(5):1741-1752. 